\title{
Activation of GPR40 attenuates chronic inflammation induced impact on pancreatic $\beta$-cells health and function
}

\author{
Mahesh Kumar Verma ${ }^{\dagger}$, Manoj Kumar Sadasivuni ${ }^{\dagger}$, Aggunda N Yateesh, Korrapati Neelima, Srikanth Mrudula, \\ Madhusudhan Reddy, Rachapalli Smitha, Sanghamitra Biswas, Bhawna Chandravanshi, Puttrevana M Pallavi, \\ Anup M Oommen, Madanahalli R Jagannath* and Baggavalli P Somesh
}

\begin{abstract}
Background: Chronic inflammation-mediated $\beta$-cell apoptosis is known to decrease $\beta$-cell mass in diabetes leading to reduced insulin secretion. Exposure to pro-inflammatory cytokines can stimulate apoptosis in pancreatic $\beta$-cells. The $G$ protein coupled receptor 40 (GPR40) is implicated for glucose induced insulin secretion. We hypothesized that GPR40 activation can protect $\beta$-cells from inflammation-induced apoptosis and restore glucose stimulated insulin secretion.

Results: By exposing NIT1 insulinoma cells and rat islets to a cocktail of pro-inflammatory cytokines (TNFa and IL1 $\beta$ ), we mimicked inflammatory signaling as seen by JNK and NFKB activation and increased mRNA levels of TNFa, IL1 $\beta$ and NOS2a. These changes were reversed by pharmacological activation of GPR40 by a specific, small molecule, CNX-011-67. Further, GPR40 activation reduced inflammation-mediated oxidative and endoplasmic reticulum (ER) stresses. Importantly, GPR40 activation decreased inflammation-induced apoptosis as measured by key markers. These impacts of GPR40 were mediated through activation of PLC, CaMKIl, calcineurin and CAMP. Cell survival was also enhanced by GPR40 activation as seen from the increased phosphorylation of Akt/PKB and enhanced expression of BCL2 and PDX1 genes. Interestingly, GPR40 activation restored both, inflammation-mediated inhibition on insulin secretion and intracellular insulin content.

Conclusions: In this study, we provide evidences that CNX-011-67, a GPR40 agonist, reduces inflammatory signaling and apoptosis in pancreatic $\beta$-cells while promoting insulin secretion and synthesis. Activation of GPR40 leads to attenuation of $\beta$-cell dysfunction caused by chronic inflammation and thus could be of immense clinical value to improve insulin secretion and $\beta$-cell survival.
\end{abstract}

Keywords: GPR40, $\beta$-cell apoptosis, $\beta$-cell survival, Inflammation, CAMP, ATP, $\mathrm{Ca}^{+2}$, Insulin content, Insulin secretion

\section{Background}

Reduction in absolute $\beta$-cell mass and/or function is linked to type-1 and type-2 diabetes mellitus [1-3]. This decrease in $\beta$-cell mass is primarily due to apoptosis driven by an increase in cytokine levels and/or a nutrient overload $[4,5]$. In fact, nutrient overload as represented by elevated levels of saturated fatty acid and glucose increases cytokine production from $\beta$-cells, activates JNK and NFKB signaling pathways [6], and triggers oxidative and ER stresses [7-11]. These conditions (nutrient overload) result in chronic low grade inflammation [12-14] which play a central role in

\footnotetext{
* Correspondence: m.r.jagannath@connexios.com

${ }^{\dagger}$ Equal contributors

Connexios Life Sciences Pvt Ltd, Bangalore, India
}

$\beta$-cell apoptosis [15]. Hence, it becomes imperative to delineate impacts of this chronic low grade inflammation and to make efforts overcome underlying severe consequences.

The $\beta$-cell mass is positively regulated by multiple mechanisms [16] and mild hyperglycemia itself can yield a compensatory increase in mass since glucose regulates $\beta$ cell growth [17]. Insulin secreted from $\beta$-cells in response to glucose activates Akt/PKB, a known inducer of cell growth and survival through the IRS-PI3K pathway. Similarly, IGF, insulin receptor, IRS2 and Akt have been associated with $\beta$-cell growth [18-23]. Thus, activation of insulin signaling by stimulating its secretion can positively impact $\beta$-cell survival and growth. For instance, GLP1 treatment, which enhances insulin secretion, has a positive impact on 
$\beta$-cell mass [24-27], and an increase in cAMP levels as mediated by GLP1 has been shown to reduce inflammatory signaling and apoptosis in $\beta$-cells [28-30].

The G-protein coupled receptor 40 (GPR40), also known as free fatty acid receptor 1 (FFAR1) is highly expressed in pancreatic $\beta$-cells. It is involved in fatty acid mediated potentiation of insulin secretion. Activation of GPR40 can increase insulin secretion [31-34] through phopsholipase-C (PLC) $-\mathrm{Ca}^{+2}$ pathway only at stimulatory glucose concentration.

Here, we propose that an increase in insulin secretion mediated by GPR40 can activate Akt/PKB to positively impact $\beta$-cell survival. Activation of GPR40 is also known to improve calcium flux in $\beta$-cells under chronic inflammatory conditions [13]. Since calcium dynamics and cAMP levels are coupled [35], we propose that GPR40 activation also attenuates inflammatory signaling.

In this study, we activated GPR40 using a specific small molecule agonist (CNX-011-67). Pharmacological activation of GPR40 by CNX-011-67 was very specific as an increase in cytoplasmic calcium flux was seen only in cells expressing GPR40 and no calcium flux was observed in cells which did not express GPR40. Moreover, CNX-011-67 mediated calcium flux was mediated through PLC pathway. Treatment of NIT1 cells and rat islets with CNX-011-67 showed a reduction in inflammatory signaling, inflammatory cytokines gene expression, cellular oxidative and ER stresses while increasing insulin secretion, intracellular insulin content and pro-survival signaling pathways. Taken together, GPR40 agonists provide a novel tool to counteract inflammation mediated $\beta$-cell dysfunction.

\section{Results}

\section{Pharmacological activation of GPR40 enhances} cytoplasmic calcium level in PLC dependent manner

GPR40 activation by small molecule agonist (CNX-011-67, $1 \mu \mathrm{M})$ significantly increased cytoplasmic calcium level (9187 AFU versus (vs) 5967 AFU of control) only in CHOK1 cells over-expressing mouse GPR40 compared to the control (Figure 1). The cytoplasmic flux induced by CNX-011-67 was PLC-dependent as treatment with a PLC inhibitor (U73122) abolished this flux (5921 AFU vs 9187 AFU of CNX-011-67; Figure 1). Normal CHOK1 cells which did not express GPR40 showed no increase in cytoplasmic calcium in response to CNX-011-67 (4813 AFU vs 4768 AFU of control, not significant). This data demonstrates that CNX-011-67 specifically activates GPR40.

\section{Activation of GPR40 attenuates cellular inflammation}

Under chronic inflammatory conditions, NIT1 cells showed a 4.4 fold increase in JNK phosphorylation (Figure 2A) and $60 \%$ decrease in $\mathrm{I} \kappa \mathrm{B}$ levels (Figure $2 \mathrm{~B}$ ) compare to untreated cells, indicative of increased NFkB signaling. Activation of GPR40 decreased inflammation-induced JNK

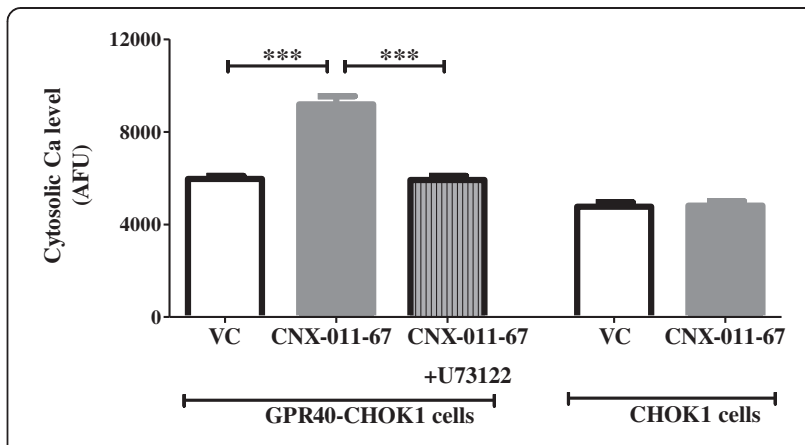

Figure 1 CNX-011-67 is a specific agonist of GPR40. CNX-011-67 induced GPR40 activation was measured in GPR40 over-expressing CHOK1 cells by its potency to increase in cytoplasmic calcium level which was abolished by PLC inhibitor (U73122) ( $\left.n=4{ }^{* * * P}<0.001\right)$. CNX-011-67 did not increase any cytoplasmic calcium level in cells not expressing GPR40.

phosphorylation (1.5 fold of control vs 4.4 fold with inflammation) and increased IkB levels (1.3 fold of control vs 0.4 fold with inflammation) in NIT1 cells (Figure 2A and B).

Gene expression of both NF- $\kappa B$ (Figure $1 C$ ) and proinflammatory cytokines such as IL1 $\beta$ (Figure 1D), TNF $\alpha$ (Figure 1E), and NOS2a (Figure $1 \mathrm{~F}$ ) was up-regulated by 2.6, 4.3, 2.2 and 7.2 fold respectively under chronic inflammation in rat islets, consistent with increased JNK and NF- $\mathrm{kB}$ activation. GPR40 activation reduced expression levels of NF- $\mathrm{KB}$ and pro-inflammatory genes to 1.5 (NF-kB), 2.5 (IL1 $\beta$ ), 1.8 (TNF $\alpha$ ) and 4.4 fold (NOS2a) respectively. These results demonstrate that activation of GPR40 can negate inflammatory signaling in $\beta$-cells.

\section{GPR40 activation reduces cellular stress in $\beta$-cells}

Since increased cellular stress is a major contributing factor for $\beta$-cell apoptosis, we investigated whether GPR40 activation influences cellular stress (oxidative and ER stress). Under conditions mimicking chronic inflammation, NIT1 cells showed 1.8 fold increase of ROS compared to control which was brought back to normal upon GPR40 activation (Figure 3A). Similarly, chronic inflammation induced CHOP (DDIT3/GADD153) gene expression up to 1.6 fold in rat islets which was brought back to 0.6 fold upon GPR40 activation (Figure 3B). Like CHOP gene expression, inflammation conditions increased BiP level (1.4 fold of control) and eIF2 $\alpha$ (1.2 fold of control) phosphorylation in NIT1 cells (Figure 3C) which were reversed upon GPR40 activation (0.6 and 0.7 fold of control respectively) (Figure $3 \mathrm{C}$ ). Taken together, these data demonstrate that activation of GPR40 significantly lowers inflammatory signaling and cellular oxidative and ER stress.

\section{GPR40 activation protects $\beta$-cells from inflammation-induced apoptosis}

To support the results from cellular oxidative and ER stress, we next showed cellular apoptosis by different methods. Treatment with chronic inflammation caused 

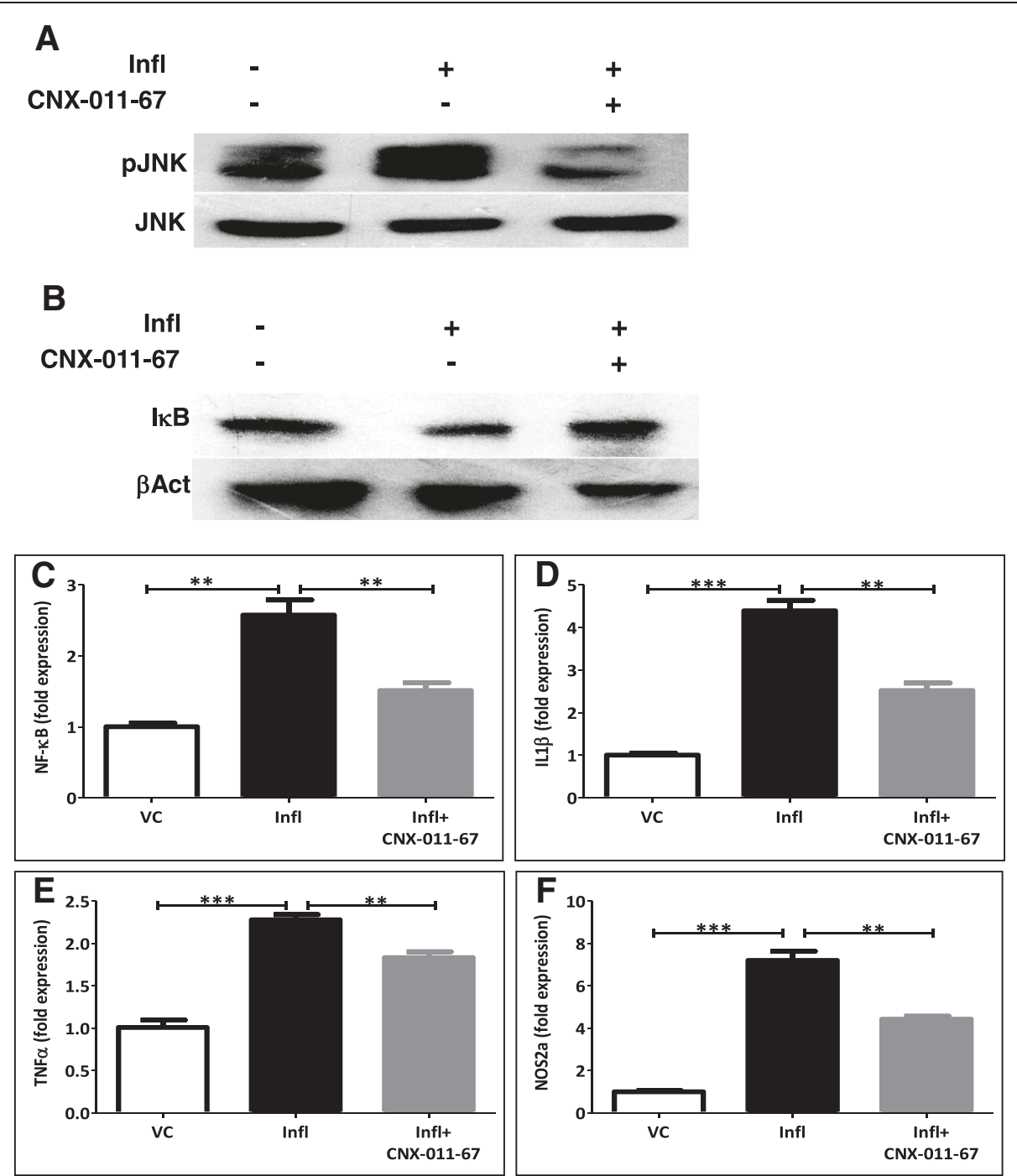

Figure 2 GPR40 activation by CNX-011-67 reduces cellular inflammation. Western blot of NIT1 cells treated with inflammatory cytokines in presence or absence of GPR40 agonist (A, B). Inflammatory cytokines (TNFa +IL1 $\beta$ ) increased JNK phosphorylation (A) and reduced IKB level (B) in NIT1 cells which were reversed by GPR40 activation. Total JNK and $\beta$-actin were used as loading control for normalization. Expression of NF-KB (C), IL1B (D), TNFa (E) and NOS2a (F) genes were up-regulated under inflammatory conditions and were down-regulated by GPR40 activation in rat islets. Gene expression was measured by qRT-PCR. $\left(n=4,{ }^{* * P}<0.01\right.$, ***P $\left.<0.001\right)$.

nuclear fragmentation in NIT1 cells as measured by a significant increase in number of condensed nuclei (Figure 4A, B). Quantification data revealed that inflammation caused more than two fold increase in these condensed nuclei $(15.4 \%$ apoptotic nuclei under inflammation compared to $6.6 \%$ in control; Figure 4D). GPR40 activation under this condition reduced nuclear fragmentation (Figure 4C) as number of condensed nuclei was decreased (10.5\% apoptotic nuclei; Figure 4C, D). Chronic inflammation enhanced cytochromec levels (Figure 4E) with a concomitant increase in Terminal deoxynucleotidyl transferase dUTP nick end labeling (TUNEL) positivity (Figure 4F). Similarly, caspase-3 activity was also increased under chronic inflammation $(163 \%$ of control; Figure 4G). GPR40 activation significantly decreased these apoptotic effects of inflammation as cytochrome-c level (Figure 4E), TUNEL positivity (Figure 4F) and caspase-3 activity were reduced ( $98 \%$ of control; Figure 4G). The GPR40mediated inhibition of caspase-3 activity was PLC-dependent since treatment with PLC inhibitor (U73122) attenuated the effect of CNX-011-67 (Figure 4G). Interestingly, PLC inhibition increased caspase- 3 activity more than chronic inflammation itself (Figure 4G). Thus, activation of GPR40 reduced inflammation-induced apoptosis of $\beta$-cells.

\section{GPR40 activation reduces apoptosis through CaMKII, Calcineurin and CAMP signaling}

In order to decipher how GPR40 activation rescued $\beta$-cell apoptosis, we measured caspase- 3 activity under chronic 
A

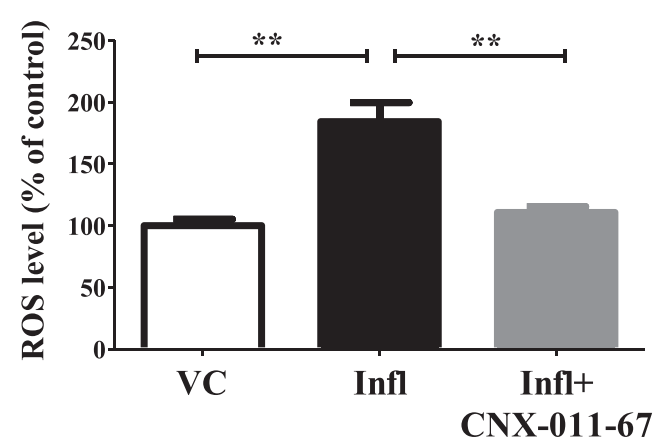

B
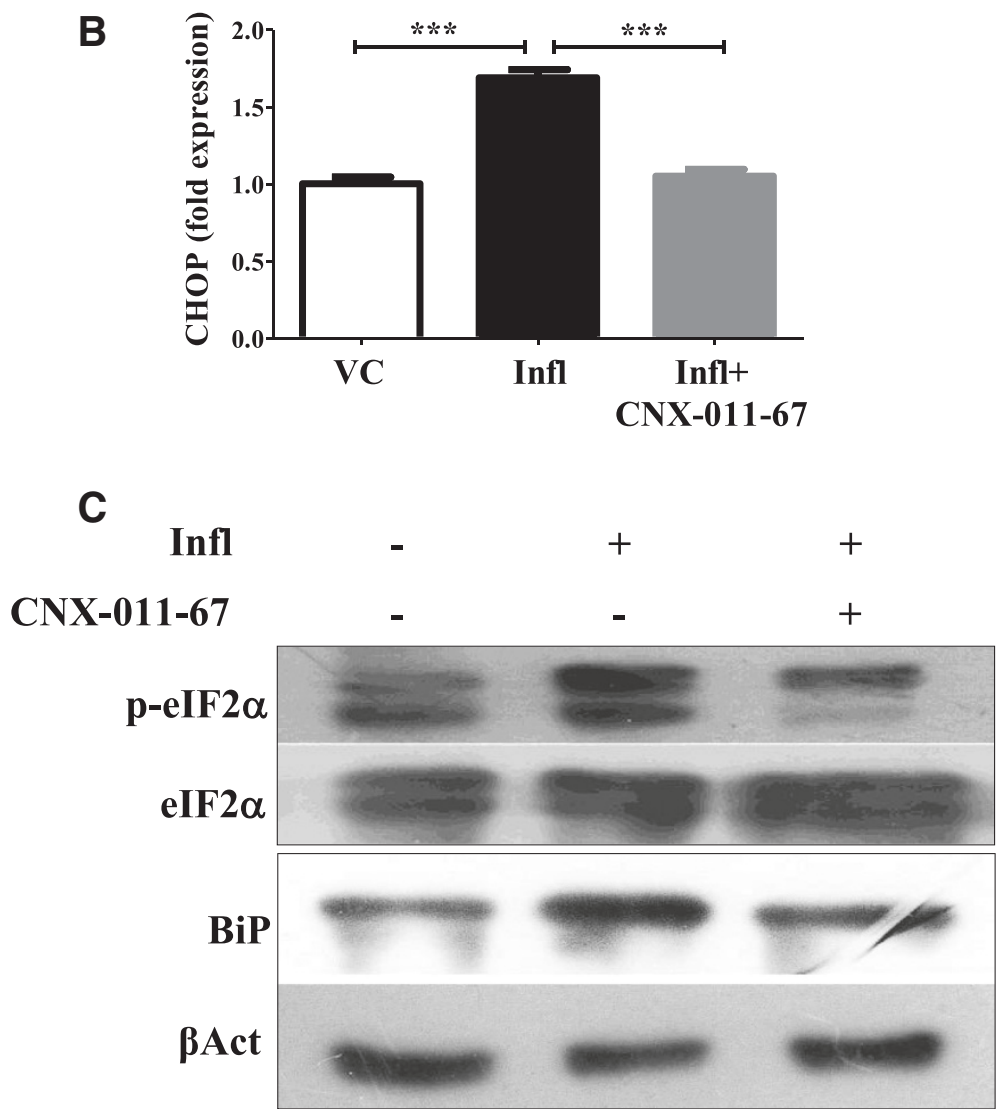

Figure 3 Chronic GPR40 activation reverses inflammation mediated increase in oxidative and ER stress. (A) NIT1 cells were treated for $72 \mathrm{~h}$ as indicated and ROS levels were measured by DCF fluorescence. ER stress was measured by expression of CHOP (DDIT3/GADD153) gene in rat islets cultured under inflammation with or without GPR40 activator (B). $\left(n=4,{ }^{* * P}<0.01,{ }^{* * *} P<0.001\right)$. (C) NIT1 cells were treated as indicated and total cell lysates were used for western blotting against BiP (GRP78/HSPA5) and p-elF2a to study ER stress. $\beta$-actin and total elF2a were used as loading control for normalization.

inflammation and used various pharmacological inhibitors to dissect out the underlying molecular mechanism. Since an increase in cytoplasmic calcium level activates CaMKII and calcineurin, we inhibited their activity using AIP and cyclosporine-A respectively $[36,37]$ and measured changes in GPR40 mediated caspase-3 activity. Activation of GPR40 reduced inflammation-induced caspase-3 activity (174\% of control under inflammation vs $120 \%$ under CNX-011-67) and this reduction was abolished by the inhibition of either CaMKII (237\% of control) or calcineurin (246\% of control) (Figure 5A). These data indicate an important role for GPR40-induced calcium flux in decreasing apoptosis. Interestingly, inhibition of either CaMKII or calcineurin increased caspase-3 activity significantly more than chronic inflammation alone (Figure 5A).

Increase in cytosolic calcium activates calcium-induced adenylate cyclase in pancreatic $\beta$-cells thereby increasing cAMP levels. Therefore, we assessed whether GPR40 


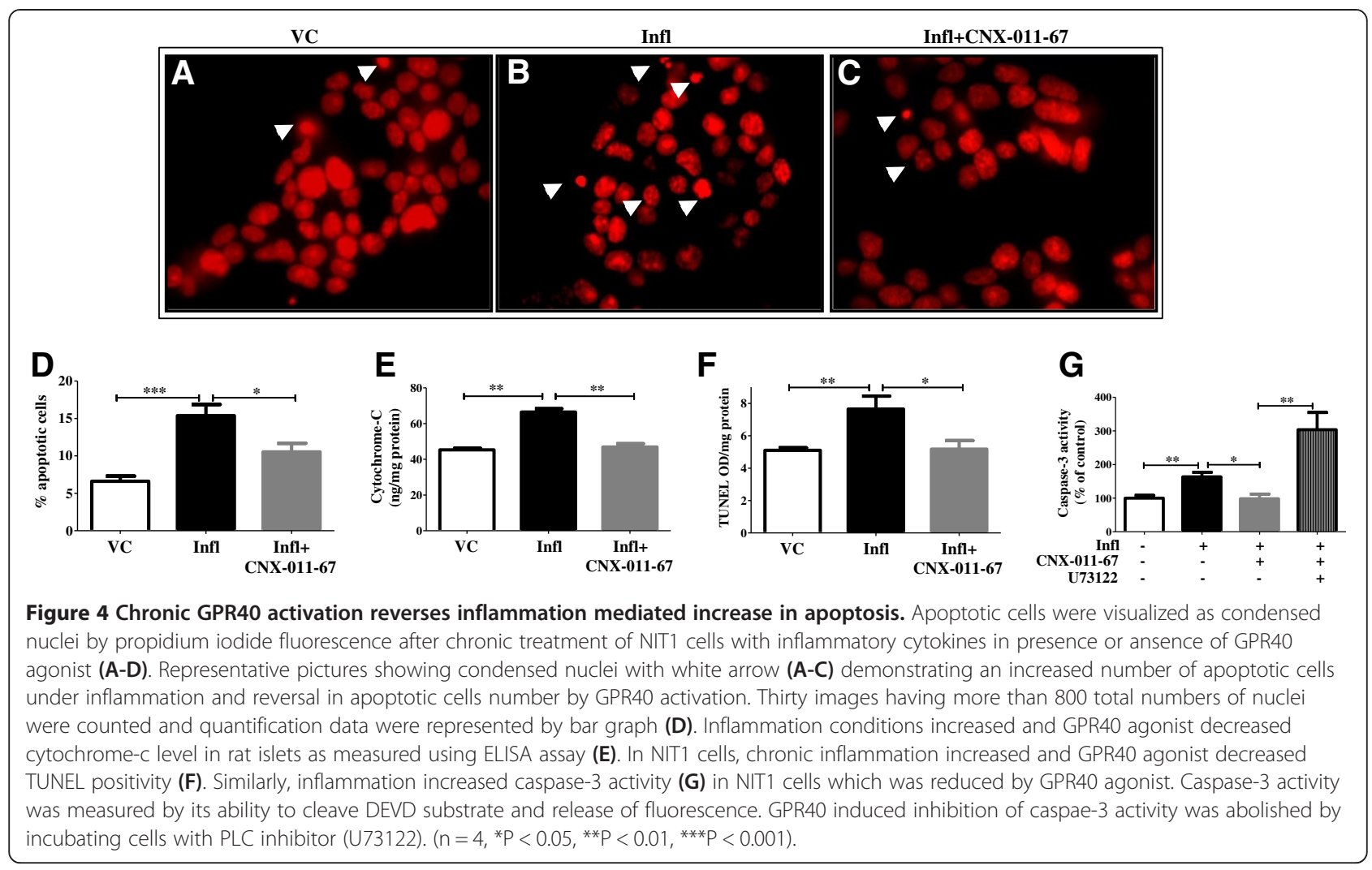

activation increased cAMP in $\beta$-cells, which may help inhibit apoptosis. Under stimulatory glucose concentrations in $\beta$-cells, we found that cAMP levels were increased (0.94picomoles $/ \mathrm{mg}$ protein at high glucose vs 0.30 picomoles/mg protein at low glucose) (Figure 5B). Under chronic inflammatory conditions, cAMP levels were significantly reduced even in the presence of stimulatory glucose concentrations (0.56picomoles/mg protein). This effect was restored by GPR40 activation (cAMP levels: 1.45picomoles/ $\mathrm{mg}$ protein) (Figure $5 \mathrm{~B}$ ). To demonstrate the role of GPR40-induced cAMP on apoptosis, we inhibited a soluble isoform of ADCY with ADCY inhibitor (KH7) [38]. Similar to the data obtained after CaMKII and calcineurin inhibition, treatment with $\mathrm{KH} 7$ abolished the impact of GPR40 on caspase- 3 activity (354\% of control with $\mathrm{KH} 7$ vs $120 \%$ with CNX-011-67) (Figure 5A). Consistent with the results seen upon PLC, CaMKII and calcineurin inhibition; ADCY inhibitor increased caspase- 3 activity in $\beta$-cells significantly more than with inflammation alone (Figures $4 \mathrm{~F}$ and $5 \mathrm{~A}$ ), indicating their role for normal $\beta$-cell functions. To better understand the role of cAMP on $\beta$-cell apoptosis, we activated $\mathrm{ADCYs}$ to increase cAMP levels using forskolin under inflammatory conditions and measured its effect on apoptosis. As seen in Figure 5A, forskolin significantly reduced caspase- 3 activity ( $40 \%$ of control vs $174 \%$ under inflammation) indicating a key role of cAMP to inhibit $\beta$ cells apoptosis. Taken together, our data demonstrate that activation of GPR40 reduces inflammation-dependent apoptosis through a mechanism involving PLC, CaMKII, calcineurin and cAMP.

\section{GPR40 activation enhances cell survival signaling}

We next examined weather GPR40 activation led to cell survival as yet another mechanism to counteract apoptosis. Activation of Akt/PKB, a known cell survival/growth signal [39], was reduced under chronic inflammatory conditions compared to control conditions ( 0.54 fold of control). GPR40 activation restored Akt/PKB phosphorylation under inflammatory conditions ( 1.51 fold of control vs 0.54 fold under inflammation) (Figure 6A). Expression of the anti-apoptotic gene BCL2, was decreased under chronic inflammatory conditions ( 0.89 fold of control). Activation of GPR40 increased BCL2 expression under these conditions (1.26 fold of control) (Figure 6B). Expression of CDKN1a/ p21, a cell cycle inhibitor, was also increased under inflammatory conditions ( 2.7 fold of control), which was reduced by GPR 40 activation (2.1 fold of control) (Figure 6C). Further, Pdx1 expression, which is required for $\beta$-cell maintenance, was reduced under inflammatory conditions $(0.35$ fold of control) and was increased upon GPR40 activation (0.81 fold of control) (Figure 6D). Thus, these data demonstrate that GPR40 activation improves $\beta$-cell survival and maintenance. 


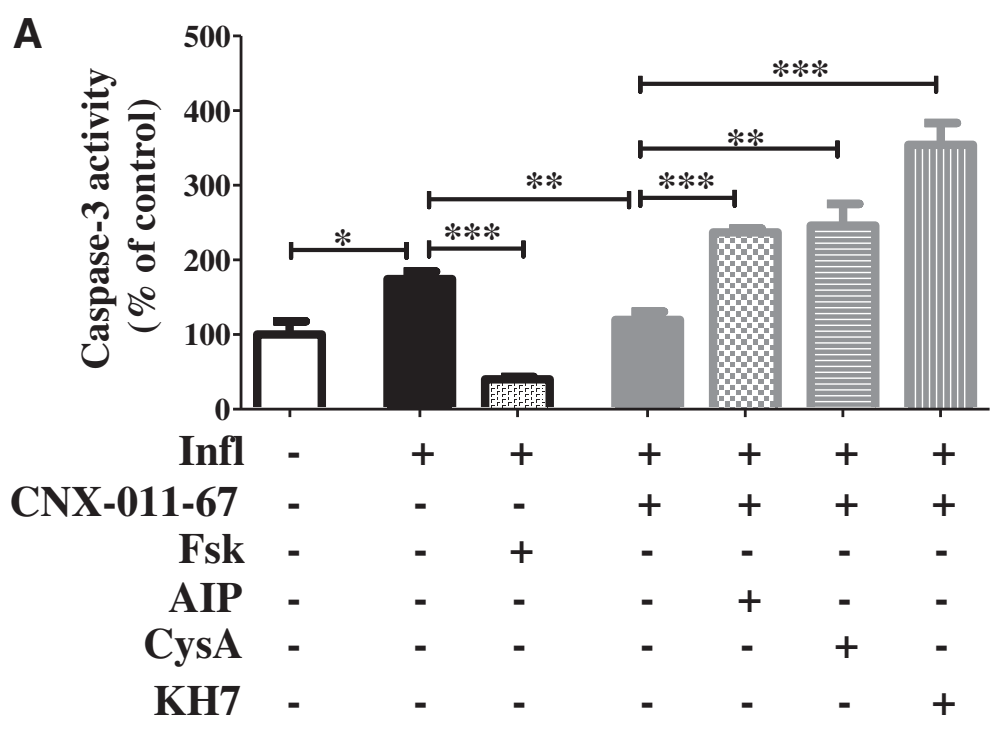

B

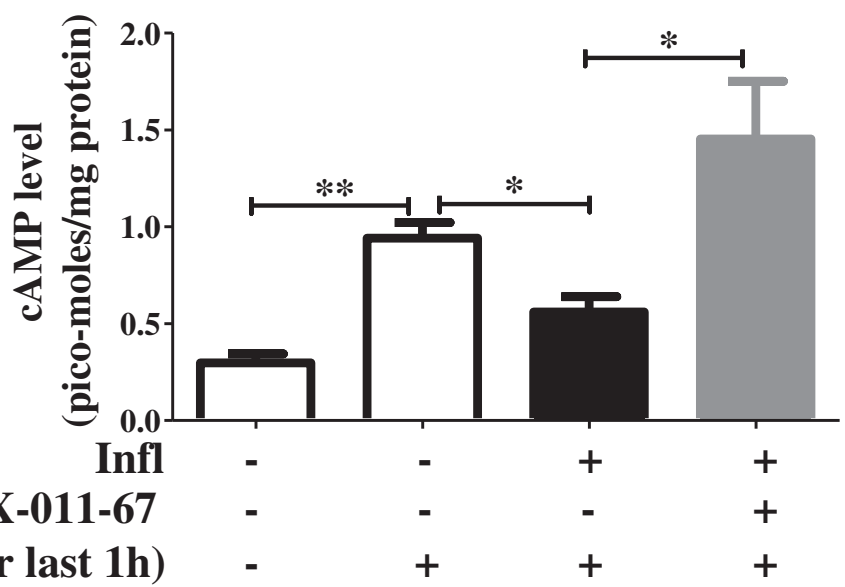

Figure 5 Activation of GPR40 reduces apoptosis through cAMP and calcium signaling. (A) NIT1 cells were cultured under inflammation conditions with or without GPR40 agonist for $72 \mathrm{~h}$ in presence of CaMKII (AIP), Calcineurin (CsA) and soluble ADCY (KH7) inhibitors or cAMP activator (Fsk) as indicated (A). GPR40 agonist and Fsk reduced inflammation induced caspase-3 activity. AIP, CysA and KH7 blocked GPR40 agonist's ability to reduced caspase-3 activity. (B) After chronic culture for $72 \mathrm{~h}$, NIT1 cells were pre-treated with low glucose containing KRBH followed by treatment for $1 \mathrm{~h}$ with low or high glucose and CAMP levels in cells were determined by enzyme immunoassay. $\left(n=4,{ }^{*} P<0.05\right.$, $\left.{ }^{* *} P<0.01,{ }^{* * *} P<0.001\right)$.

GPR40 activation improves insulin synthesis and secretion To verify that GPR40 activation plays a role in decreasing inflammation, we measured its impact on insulin secretion as an indicator of overall $\beta$-cell function. We observed impaired glucose-stimulated insulin secretion under chronic inflammatory conditions (0.07 ng/islet vs $0.22 \mathrm{ng} /$ islet under control), which was significantly improved by GPR40 activation (0.20 ng/islet) (Figure 7A). GPR40 activation also led to an increase in insulin secretion from control islets (Additional file 1). Further, GPR40 activation increased cellular ATP (24nano-moles/mg protein), which is required for insulin secretion and was decreased under chronic inflammation (15nano-moles/mg protein vs 36nano-moles/ mg protein under control condition) (Figure 7B). In keeping with these observations, we subsequently assessed the impact of GPR40 activation on insulin synthesis. Expression of insulin gene was significantly reduced under chronic inflammatory conditions (0.92 fold of control) (Figure 7C). Activation of GPR40 under these conditions increased insulin gene expression (1.14 fold of control) (Figure 7C). Consistent with the findings of insulin gene expression and insulin secretion, intracellular insulin content was decreased under chronic inflammatory conditions $(1.5 \mathrm{ng} /$ islet vs $2.4 \mathrm{ng}$ /islet under control) and was restored by GPR40 activation (2.0 ng/islet) (Figure 7D).

Based on our findings, we provide a schematic representation of how GPR40 activation led to counteract inflammation mediated deleterious effects on pancreatic $\beta$-cells (Figure 8). Exposure to inflammatory cytokines led to activation of NFKB and JNK which causes increased expression 


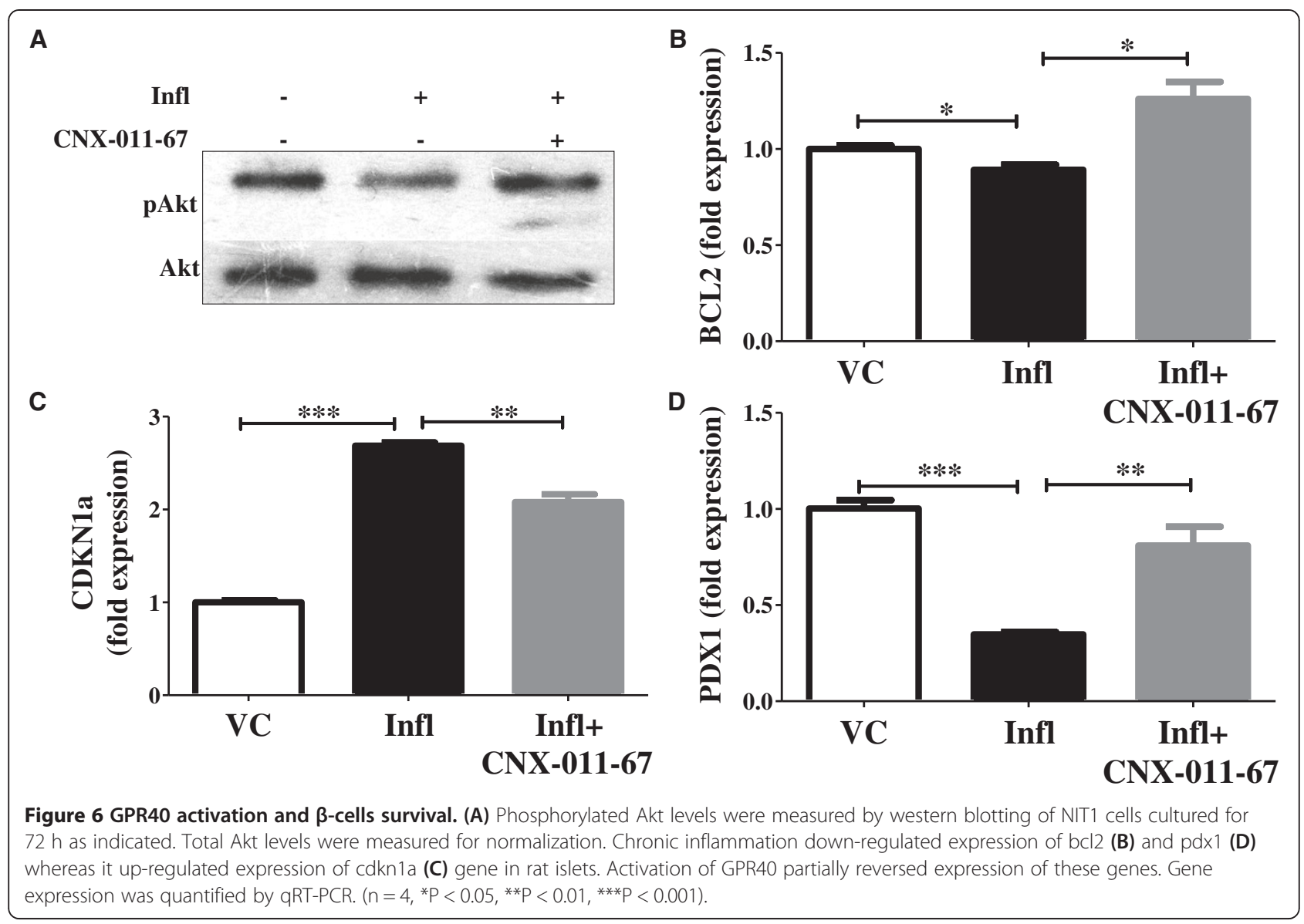

of pro-inflammatory cytokines, thus creating a positive feed back loop. NFKB and JNK activation lead to increase oxidative and ER stress, cytochrome-c release from mitochondria and Caspase-3 activation thereby causing apoptosis and reduction in insulin synthesis and secretion. Activation of GPR40 augments cytoplasmic calcium and cAMP levels which potentiate insulin synthesis and secretion thereby autocrine cell survival signaling. Moreover, elevated cAMP levels reduce activation of NFKB and JNK and hence block inflammatory signaling (Figure 8).

\section{Discussion}

In this present study we showed that activation of GPR40 by a small molecule, CNX-011-67, rescued inflammationmediated apoptosis in pancreatic $\beta$-cells. We demonstrated that chronic inflammation, which has been shown to severely impact $\beta$-cells' function and mass [14], caused an augmentation in cellular oxidative and ER stress, expression of pro-inflammatory cytokines genes and apoptosis. We found that all these impacts of chronic inflammation were reversed by GPR40 activation. Also we have observed no significant change in the expression of GPR40 under inflammation condition with or without the receptor activation (data not shown).
Chronic inflammation has been a mechanism implicated for $\beta$-cell apoptosis in both type- 1 and type- 2 diabetes $[4,40-42]$. Hence, it is important to counteract inflammationmediated changes in $\beta$-cells in order to protect them from apoptosis. Therefore, we evaluated the potential of GPR40 activation as a mechanism to neutralize inflammation mediated consequences. We have activated GPR40 using a small molecule agonist (CNX-011-67) which showed an increase in calcium flux. CNX-011-67 is a specific GPR40 agonist as it enhanced calcium flux only in cells expressing GPR40. Moreover, inhibition of PLC reversed CNX-011-67 induced calcium flux as GPR40 activation mediates its effect via PLC$\mathrm{Ca}^{2+}$ pathway [31].

Since, inflammatory cytokines exert their effects through activation of JNK and NFKB, we have showed that treatment with GPR40 agonist was able to reduce their activation. These findings were also supported by a decrease in pro-inflammatory cytokines gene expression by GPR40 agonist. Activation of JNK and NFKB has been shown to up-regulate these pro-inflammatory cytokines [43], hence their reduced activation by GPR40 agonist led to a decreased expression of these genes (TNF $\alpha$, IL1 $\beta$, Nos2a). Thus, GPR40 activation not only blocked impact of those inflammatory cytokines added to culture medium but also 


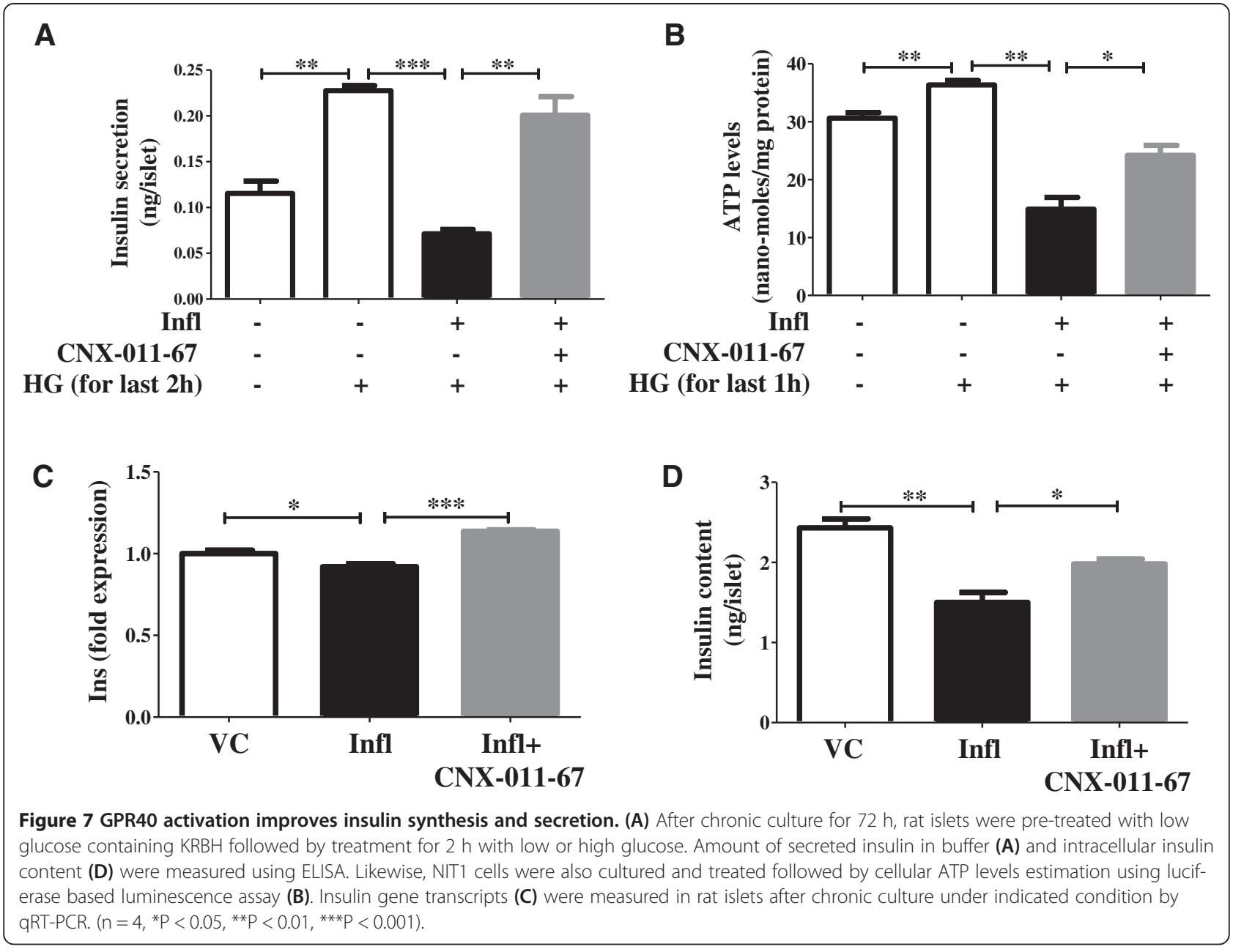

inhibited their production from $\beta$-cells thereby plunging chronic low grade inflammation maintenance.

Elevated cellular oxidative and ER stress under nutrient overload condition can cause $\beta$-cells apoptosis [7-11]. In fact, we also observed increased oxidative and ER stress after pro-inflammatory cytokines treatment which was abolished by GPR40 agonist. Under inflammatory conditions, an increased level of $\beta$-cell death was observed as measured by cytochrome-c release, TUNEL positivity, Caspase- 3 activation and nuclear fragmentation. In consistent with above mentioned findings with GPR40 activation, we observed diminished apoptosis in pancreatic $\beta$-cells upon GPR40 agonist treatment.

In order to dissect the mechanism by which GPR40 activation reduced $\beta$-cells apoptosis, we used various pharmacological agents to inhibit or activate key intracellular signaling pathways. As expected, inhibition of PLC signaling by U73122 abolished GPR40 agonist impact on apoptosis because GPR40 exerts its effect by PLC activation. Interestingly, PLC inhibition caused a higher increase in Caspase-3 activity compared to inflammation alone, indicating its importance for normal physiological functions of $\beta$-cells. In fact, elevated glucose level can cause activation of PLC signaling in islets [44]. Activation of PLC leads to ER calcium release; hence we next tested the role of calcium signaling for GPR40 induced reduction in apoptosis. Increase in cytoplasmic calcium can lead to activation of calcium-calmodulin dependent protein kinase (CaMK) and calcineurin-NFAT pathways. In order to specify which of these pathways was involved in the ability of GPR40 to counteract inflammation induced apoptosis, we inhibited each of these and observed their effect. Inhibition of CaMKII, the major isoform present in $\beta$-cells, showed a pronounced increase in caspase- 3 activity. Similar results were obtained after calcineurin inhibition. Interestingly, inhibition of either CaMKII or calcineurin caused increased caspase- 3 activity higher than that achieved by inflammation itself, signifying their importance in normal physiology of $\beta$-cells.

Increase in cytoplasmic calcium level is coupled with an increase in cAMP level due to presence of calcium activated $A D C Y$ in $\beta$-cells. We tested the possibility that increase in cytoplasmic calcium level by GPR40 activation would lead to a corresponding increase in cAMP level. 


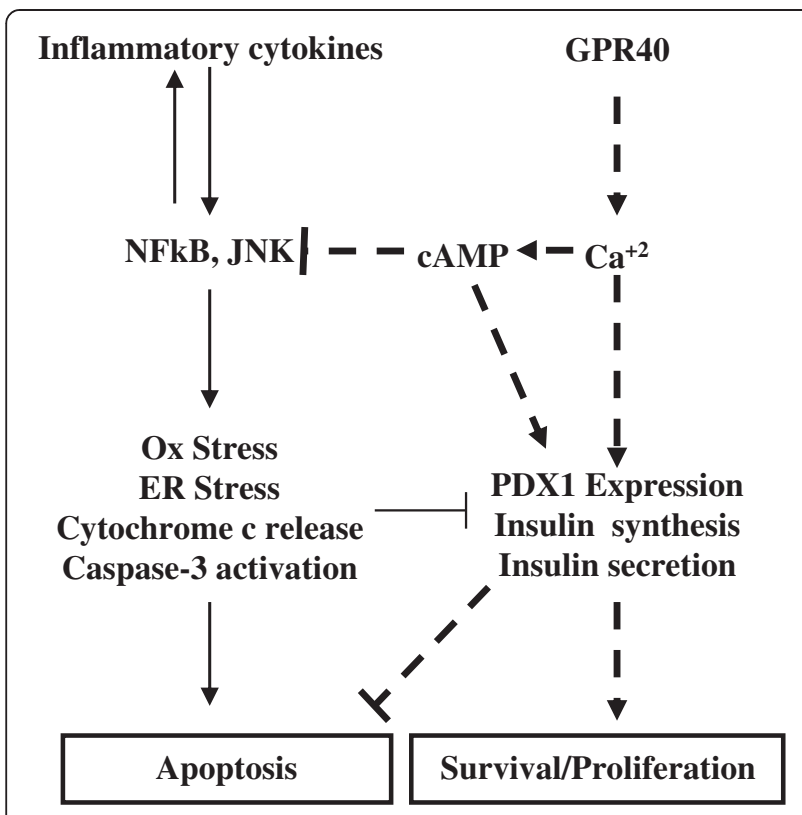

Figure 8 Schematic representation of mechanisms involved for $\beta$-cells apoptosis caused by inflammatory cytokines exposure and its reversal by GPR40 activation. Pointed arrows represent activatory signals and blunted lines represent inhibitory signals. Signals propagated from inflammatory cytokines are shown as normal arrows while signals propagated from GPR40 activation are shown as broken arrows/lines.

We found that cAMP levels were decreased under inflammation condition and were restored by GPR 40 agonist. To demonstrate the importance of GPR40-induced cAMP level for caspase-3 activity, we inhibited a soluble isoform of ADCY present in $\beta$-cells which is known to mediate cAMP oscillation [38,45]. Similar to data obtained with PLC, CaMKII and calcineurin inhibitor; inhibition of sADCY caused a drastic increase in caspase-3 activity at levels higher than that achieved with inflammation alone. Since these inhibitors are known to suppress insulin secretion, their exposure might have reduced autocrine survival 'insulin-PI3K-Akt' signaling. In contrast, increase in cAMP level by forskolin led to a significant reduction in caspase3 activity indicating an independent role of cAMP for reduction in $\beta$-cell death. Treatment with GLP1, which can also increase cAMP levels, has been shown to reduce apoptosis in pancreatic $\beta$-cells [28-30]. Thus, our data collectively demonstrate that GPR40 activation relayed its signal to multiple arms of intracellular signaling pathways to reduce inflammation mediated apoptosis.

GPR40 activation not only inhibited $\beta$-cell apoptosis but also activated cell survival pathways. Its activation led to an increase in ATP level which together with elevated $\mathrm{Ca}^{2+}$ and cAMP level caused a significant increase in glucose-stimulated insulin secretion. This secreted insulin can lead to Akt/PKB phosphorylation in an autocrine manner. The level of phosphorylated Akt, a well known marker for cell survival and proliferation, was reduced under chronic inflammation conditions, together with a reduction in insulin secretion. GPR40 agonist reversed this decrease in pAkt level. Similarly, BCL2 and PDX1 expression were reduced under inflammation and were restored by GPR40 agonist. PDX1 maintains $\beta$-cell phenotype and also regulates insulin synthesis. In consistent with PDX1 data, inflammation reduced insulin gene transcription and intracellular insulin content and their levels were restored by GPR40 agonist. Under this condition we did not observe any change in the glucagon expression in rat islets (data not shown). This is consistence with the fact that GPR40 expression in predominant only in $\beta$-cells.

We have earlier showed that activation of GPR40 by oral administration of CNX-011-67 in male ZDF rats reduces $\beta$-cells apoptosis, increases insulin and PDX1 positive cell number and insulin secretion [46]. It should be noted that ZDF rat is an animal model of diabetes having high chronic systemic inflammation $[47,48]$. Hence, our in vitro data are in agreement with in vivo findings. Taken together, our data demonstrate that GPR40 activation by CNX-011-67 reduces inflammation induced apoptosis, enhances $\beta$-cell survival and improves $\beta$-cell function as measured by insulin synthesis and secretion.

\section{Conclusions}

In this study, we demonstrated that activation of GPR40, which is implicated for glucose induced insulin secretion, can rescue pancreatic $\beta$-cells from inflammation induced dysfunction. GPR40 activation increased cytoplasmic calcium level in a PLC dependent manner. We also established the molecular link of GPR40 activation and downstream calcium flux to cellular cAMP levels. GPR40 mediated its impact through CaMKII, NFAT and cAMP as their inhibition totally reversed the protective impact on $\beta$-cells apoptosis. Moreover, GPR40 activation promoted $\beta$-cell survival signaling which was impaired under chronic inflammatory conditions. These survival signaling might have been initiated by insulin as GPR40 activation led to enhanced insulin secretion. This study provides basis for the development of GPR40 activators that might be an effective therapeutic strategy to combat $\beta$-cells dysfunction caused by chronic inflammation.

\section{Methods}

\section{Rat islet isolation}

Male Wistar rats (8-10 weeks, $180-240$ gm body weight; Charles River Lab, USA) were used for islet isolation. All experimental protocols have been approved by Institutional Animal Ethics Committee (IAEC) of Connexios Life Sciences, which is recognized by the Committee for the Purpose of Control and Supervision on Experiments on Animals (CPCSEA), India. Excess anesthesia was used to kill the animals and the pancreata were cut into 1-2 mm 
pieces in HBSS (pH7.4; Sigma) followed by digestion with collagenase-II (2 mg/ml in HBSS; Sigma) at $37^{\circ} \mathrm{C}$ for $20 \mathrm{~min}$. The reaction was stopped by adding two volumes of culture medium (RPMI containing 10\%FBS; Invitrogen) and gently triturated. The cell pellet was obtained after centrifugation at $100 \mathrm{Xg}$ for $5 \mathrm{~min}$ and then washed resuspended in $4 \mathrm{ml}$ of Histopaque (1.119 gm/ml; Sigma). Histopaque $(1.077 \mathrm{mg} / \mathrm{ml} ; 3 \mathrm{ml})$ followed by culture medium were overlaid on this suspension and density gradient centrifugation was carried out. The islets were recovered from the interface of culture medium and Histopaque 1.077 and then washed with HBSS. The purified islets were then handpicked under a stereo-zoom microscope (Nikon, Japan) and used for subsequent experiments.

\section{Cell culture and treatment}

NIT1 cell line (ATCC) was cultured under either control or inflammation (TNF $\alpha+$ IL1 $\beta$, both $10 \mathrm{ng} / \mathrm{ml}$ ) conditions for $72 \mathrm{~h}$ in presence or absence of GPR40 agonist (CNX011-67, $1 \mu \mathrm{M})$. For Caspase-3 assay, NIT1 cells were cultured for $72 \mathrm{~h}$ in presence or absence of the following pharmacological modulators- PLC inhibitor (U73122, $2 \mu \mathrm{M}$ ), soluble adenylate cyclase (ADCY) inhibitor (KH7, $30 \mu \mathrm{M})$, non-specific ADCY activator (forskolin, $10 \mu \mathrm{M}$ ), calciumcalmodulin kinase-II (CaMKII) inhibitor (AIP, $1 \mu \mathrm{M})$ and calcineurin inhibitor (Cyclosporin A: CysA, $1 \mu \mathrm{M}$ ). Treatments for rat islets were the same as described for NIT1 cells above.

\section{Calcium flux}

CHOK1 cells over-expressing mouse GPR40 (Cytobox) were plated in 96-black well plate. Cells were washed with $\mathrm{KRBH}$ and loaded with Fluo-4-AM, a calcium indicator fluorescent dye (Invitrogen), at $37^{\circ} \mathrm{C}$ for $1 \mathrm{~h}$. Basal fluorescence readings were taken at $485 \mathrm{~nm}$ excitation and at $520 \mathrm{~nm}$ emission. Cells were then induced with GPR40 agonist (CNX-011-67, $1 \mu \mathrm{M})$ in presence or absence of PLC inhibitor (U73122, $10 \mu \mathrm{M}$ ) followed by fluorescence readings for induced calcium flux. Changes in fluorescence readings between basal and induced conditions in different treatments were defined as arbitrary fluorescence units (AFU). Normal CHOK1 cells not expressing GPR40 were used as a control for the experiment.

\section{Western blotting}

After incubation, NIT1 cells were lysed and total proteins were resolved by SDS-PAGE followed by transfer to nitrocellulose membrane. After blocking with BSA, the membrane was incubated overnight at $4^{\circ} \mathrm{C}$ with primary antibody followed by washing and incubation with HRPconjugated secondary antibody. Primary antibodies used are pAKT, AKT, pJNK, JNK, IkB and $\beta$-actin (Cell Signaling Technology). The blot was developed using chemiluminescence substrate (Pierce) and exposed to X-ray film.
Densitometric analyses were carried out using Image-J (NIH) software.

RNA isolation, reverse transcription and quantitative real time polymerase chain reaction ( $q P C R$ )

Total RNA was extracted from treated islets using Trizol reagent (Sigma, St. Louis, MO, USA), and was used as a template for cDNA synthesis with reverse transcriptase and random hexamer primers (ABI, CA, USA). Quantification of gene expression was done using SYBR Green PCR Master Mix (Eurogenetic, Belgium) using the ABI7500 fast thermal cycler. We examined expression for those genes whose primers generated a single peak in the melting curve analysis and a single, specific band in agarose gel electrophoresis. Genes analyzed in this study were NF- $\kappa$ B, IL1 $\beta$, TNF $\alpha$, NOS2a, CHOP, BCL2, CDKN1A, PDX1 and Insulin. $\beta$-actin or $18 \mathrm{~S}$ rRNA was used as a housekeeping gene control. The primer sequences are provided in the Additional file 2.

\section{Caspase- 3 assay}

After $72 \mathrm{~h}$ of incubation, NIT1 cells were lysed in lysis buffer followed by estimation of Caspase-3 activity. Caspase-3 activity was measured by cleavage of its substrate (Ac-DEVD-R110; Invitrogen) and release of fluorescent R110 which was measured at $485 \mathrm{~nm}$ excitation and $530 \mathrm{~nm}$ emission. Activity of caspase-3 (as nano-moles of R110 released) was normalized to total cellular protein. Change in Caspase-3 activity under different conditions was represented as $\%$ of control.

\section{Nuclear fragmentation assay}

NIT1 cells were fixed after chronic treatments of inflammation and GPR40 agonist. Nuclei were stained with propidium iodide (PI) and morphology of nuclei was studied microscopically. Images were captured at $100 \mathrm{X}$ magnification for analysis. For each set more than 800 nuclei were counted and fragmented, shrunken or condensed nuclei were taken to indicate apoptotic nuclei. Data were presented as\% of apoptotic nuclei.

\section{Cytochrome-c assay}

Rat islets were treated under inflammation and GPR40 agonist. After treatment media was removed, islets were washed three times with PBS, followed by solubilization of the cell membrane using $1 \mathrm{xPBS}$ and $0.5 \%$ triton-X100. Cytochrome $C$ levels were measured according to the manufacturer's instructions (RnD Biosystems).

\section{TUNEL assay}

After chronic treatment with inflammation and GPR40 agonist, NIT1 cells were washed with PBS and fixed with $1 \%$ paraformaldihyde. Fragmented DNA was labeled using ApopTag ${ }^{\ominus}$ Peroxidase Apoptosis Detection Kit (Millipore) 
and peroxidase activity was measured using TMB$\mathrm{H}_{2} \mathrm{O}_{2}$. TUNEL levels were normalized to total cellular protein amount.

Insulin secretion and intra-cellular insulin content analysis Following chronic treatment of inflammation and GPR40 agonist, size-matched islets were picked under a microscope and transferred into 24-well plates containing $1 \mathrm{ml}$ $\mathrm{KRBH}$ buffer (2.5 mM glucose)/well and pre-incubated at $37^{\circ} \mathrm{C} / 5 \% \mathrm{CO}_{2}$ for $1 \mathrm{~h}$. The buffer was then carefully removed from the wells and the islets were induced in fresh KRBH buffer $(250 \mu \mathrm{l} /$ well $)$ containing low $(2 \mathrm{mM})$ or high glucose $(11 \mathrm{mM})$ at $37^{\circ} \mathrm{C} / 5 \% \mathrm{CO}_{2}$ for $2 \mathrm{~h}$. The supernatant was removed from the islets and stored at $-70^{\circ} \mathrm{C}$ for ELISA. Secreted insulin was measured in the KRBH buffer using ELISA (Mercodia) as per manufacturer's instructions. Insulin secretion was represented as the amount of insulin secreted (ng) per islet. Islet lysates were used to measure intracellular insulin content, which was also represented as the amount of insulin (ng) per islet.

\section{Measurement of ATP and cAMP level}

NIT1 cells were cultured under inflammation and GPR40 agonist and then washed with KRBH buffer followed by pre-incubation at $37^{\circ} \mathrm{C} / 5 \% \mathrm{CO}_{2}$ for $1 \mathrm{~h}$ in the same buffer. Subsequently, cells were treated with low $(2 \mathrm{mM})$ or high glucose $(11 \mathrm{mM})$ at $37^{\circ} \mathrm{C} / 5 \% \mathrm{CO}_{2}$ for $1 \mathrm{~h}$ followed by estimation on cAMP or ATP in cell lysates. ATP determination kit (Invitrogen) and Amersham cAMP Biotrak Enzymeimmunoassay (EIA) System (GE Healthcare) were used for the estimation of ATP and cAMP respectively.

\section{Measurement of cellular ROS level}

After chronic treatments of inflammation and GPR40 agonist for $72 \mathrm{~h}$, NIT1 cells were loaded for $1 \mathrm{~h}$ with DCFH-DA dye for ROS measurement (Invitrogen). Cells were lysed and lysates were transferred to 96-black well plate to measure increase in DCF fluorescence at $485 \mathrm{~nm}$ excitation and $528 \mathrm{~nm}$ emission. Amount of ROS was normalized to total cellular DNA which was measured using bis-benzamide fluorescence at $360 \mathrm{~nm}$ exication and $460 \mathrm{~nm}$ emission.

\section{Statistical analysis}

Data are expressed as mean \pm SEM and significance was calculated using the unpaired Student's t-test. "indicates $\mathrm{p}<0.05$; **indicates $\mathrm{p}<0.01$; ***indicates $\mathrm{p}<0.001$ compared to the respective control. Each data point consists of four individual replicates and experiments were repeated to check reproducibility. Miscrosoft Excel was used for statistical analysis.

\section{Additional files}

Additional file 1: Impact of GPR40 agonist (CNX-011-67) on insulin secretion from rat islets.

Additional file 2: List of primers used in the study.

\section{Competing interest}

The authors do not declare any competing interest.

\section{Authors' contribution}

VMK, SMK, YAN, NK, MS, MR, SR, SB, BC and PPM carried out experiments; VMK, SMK, SBP, MOA and JMR planned/executed the study and analyzed data. VMK, SMK, SBP wrote the manuscript. All authors read and approved the final manuscript.

\section{Acknowledgements}

The authors thank Niketa Pawar, Naved Pasha, Usha Padukone and Jayalaxmi Shetty at Connexios Life Sciences Pvt Ltd. for their assistance in the study. The authors are grateful to Suri Venkatachalam, Usha Narayanan,

Raghavendra Rao, M.V Venkataranganna, R Mathiyazhagan, Aseem Premnath and Swapnika Ramu at Connexios Life Sciences Pvt Ltd. for critical review of the manuscript and helpful discussions.

Funding

Financial support for this study was provided by Connexios Life sciences Pvt Ltd, Bangalore.

Received: 14 January 2014 Accepted: 24 June 2014

Published: 30 June 2014

\section{References}

1. Weir GC, Bonner-Weir S: Five stages of evolving beta-cell dysfunction during progression to diabetes. Diabetes 2004, 53:S16-21.

2. Donath MY, Halban PA: Decreased beta-cell mass in diabetes: significance, mechanisms and therapeutic implications. Diabetologia 2004, 47:581-589.

3. Prentki M, Nolan CJ: Islet beta cell failure in type 2 diabetes. J Clin Invest 2006, 116:1802-1812.

4. Eizirik DL, Mandrup-Poulsen T: A choice of death-the signal-transduction of immune-mediated beta-cell apoptosis. Diabetologia 2001, 44:2115-2133.

5. Cnop M, Welsh N, Jonas JC, Jörns A, Lenzen S, Eizirik DL: Mechanisms of pancreatic beta-cell death in type 1 and type 2 diabetes: many differences, few similarities. Diabetes 2005, 54:S97-107.

6. Igoillo-Esteve M, Marselli L, Cunha DA, Ladrière L, Ortis F, Grieco FA, Dotta F, Weir GC, Marchetti P, Eizirik DL, Cnop M: Palmitate induces a pro-inflammatory response in human pancreatic islets that mimics CCL2 expression by beta cells in type 2 diabetes. Diabetologia 2010, 53:1395-1405.

7. Carlsson C, Borg LA, Welsh N: Sodium palmitate induces partial mitochondrial uncoupling and reactive oxygen species in rat pancreatic islets invitro. Endocrinology 1999, 140:3422-3428.

8. Kharroubi I, Ladrière L, Cardozo AK, Dogusan Z, Cnop M, Eizirik DL: Free fatty acids and cytokines induce pancreatic beta-cell apoptosis by different mechanisms: role of nuclear factor-kappaB and endoplasmic reticulum stress. Endocrinology 2004, 145:5087-5096.

9. Karaskov E, Scott C, Zhang L, Teodoro T, Ravazzola M, Volchuk A: Chronic palmitate but not oleate exposure induces endoplasmic reticulum stress, which may contribute to INS-1 pancreatic beta-cell apoptosis. Endocrinology 2006, 147:3398-3407.

10. Morgan D, Oliveira-Emilio HR, Keane D, Hirata AE, Santos da Rocha M, Bordin S, Curi R, Newsholme P, Carpinelli AR: Glucose, palmitate and pro-inflammatory cytokines modulate production and activity of a phagocyte-like NADPH oxidase in rat pancreatic islets and a clonal beta cell line. Diabetologia 2007, 50:359-369.

11. Cunha DA, Hekerman P, Ladrière L, Bazarra-Castro A, Ortis F, Wakeham MC, Moore F, Rasschaert J, Cardozo AK, Bellomo E, Overbergh L, Mathieu C, Lupi R, Hai T, Herchuelz A, Marchetti P, Rutter GA, Eizirik DL, Cnop M: Initiation and execution of lipotoxic ER stress in pancreatic beta-cells. J Cell Sci 2008, 15:2308-2318

12. Pitsavos C, Tampourlou M, Panagiotakos DB, Skoumas Y, Chrysohoou C, Nomikos T, Stefanadis C: Association Between Low-Grade Systemic 
Inflammation and Type 2 Diabetes Mellitus Among Men and Women from the ATTICA Study. Rev Diab Stud 2007, 4:98-104.

13. Dula SB, Jecmenica M, Wu R, Jahanshahi P, Verrilli GM, Carter JD, Brayman KL, Nunemaker CS: Evidence that low-grade systemic inflammation can induce islet dysfunction as measured by impaired calcium handling. Cell Calcium 2010, 48:133-142.

14. Odegaard JI, Chawla A: Connecting Type 1 and Type 2 Diabetes through Innate Immunity. Cold Spring Harb Perspect Med 2012, 2:a007724.

15. Zhang Y, Xu M, Zhang S, Yan L, Yang C, Lu W, Li Y, Cheng H: The role of G protein-coupled receptor 40 in lipoapoptosis in mouse beta-cell line NIT-1. J Mol Endocrinol 2007, 38:651-661.

16. Bonner-Weir S: Perspective: postnatal pancreatic beta cell growth. Endocrinology 2000, 141:1926-1929.

17. Bonner-Weir S, Deery D, Leahy JL, Weir GC: Compensatory growth of pancreatic beta-cells in adult rats after short-term glucose infusion. Diabetes 1989, 38:49-53.

18. Kubota N, Tobe K, Terauchi Y, Eto K, Yamauchi T, Suzuki R, Tsubamoto Y, Komeda K, Nakano R, Miki H, Satoh S, Sekihara H, Sciacchitano S, Lesniak M, Aizawa S, Nagai R, Kimura S, Akanuma Y, Taylor SI, Kadowaki T: Disruption of insulin receptor substrate 2 causes type 2 diabetes because of liver insulin resistance and lack of compensatory beta-cell hyperplasia. Diabetes 2000, 49:1880-1889.

19. Rhodes CJ: IGF-I and GH post-receptor signaling mechanisms for pancreatic beta-cell replication. J Mol Endocrinol 2000, 24:303-311.

20. Bernal-Mizrachi E, Wen W, Stahlhut S, Welling CM, Permutt MA: Islet beta cell expression of constitutively active Akt1/PKB alpha induces striking hypertrophy, hyperplasia, and hyperinsulinemia. J Clin Invest 2001, 108:1631-1638

21. Tuttle RL, Gill NS, Pugh W, Lee JP, Koeberlein B, Furth EE, Polonsky KS, Naji A, Birnbaum MJ: Regulation of pancreatic beta-cell growth and survival by the serine/threonine protein kinase Akt1/PKBalpha. Nat Med 2001, 7:1133-1137.

22. Kulkarni RN: New insights into the roles of insulin/IGF-I in the development and maintenance of beta-cell mass. Rev Endocr Metab Disord 2005, 6:199-210.

23. Ueki K, Okada T, Hu J, Liew CW, Assmann A, Dahlgren GM, Peters JL, Shackman JG, Zhang M, Artner I, Satin LS, Stein R, Holzenberger M, Kennedy RT, Kahn CR, Kulkarni RN: Total insulin and IGF-I resistance in pancreatic beta cells causes overt diabetes. Nat Genet 2006, 38:583-588.

24. Drucker DJ: The glucagon-like peptides. Endocrinology 2001, 142:521-527.

25. MacDonald PE, El-Kholy W, Riedel MJ, Salapatek AM, Light PE, Wheeler MB: The multiple actions of GLP-1 on the process of glucose-stimulated insulin secretion. Diabetes 2002, 51:S434-S442.

26. Drucker DJ: Glucagon-like peptides: regulators of cell proliferation, differentiation, and apoptosis. Mol Endocrinol 2003, 17:161-171.

27. List JF, Habener JF: Glucagon-like peptide 1 agonists and the development and growth of pancreatic beta-cells. Am J Physiol Endocrinol Metab 2004, 286:E875-E881.

28. Li L, El-Kholy W, Rhodes CJ, Brubaker PL: Glucagon-like peptide-1 protects beta cells from cytokine-induced apoptosis and necrosis: role of protein kinaseB. Diabetologia 2005, 48:1339-1349.

29. Ferdaoussi M, Abdelli S, Yang JY, Cornu M, Niederhauser G, Favre D, Widmann C, Regazzi R, Thorens B, Waeber G, Abderrahmani A: Exendin-4 protects beta-cells from interleukin-1 beta-induced apoptosis by interfering with the c-Jun NH2-terminal kinase pathway. Diabetes 2008, 57:1205-1215.

30. Kim JY, Lim DM, Moon Cl, Jo KJ, Lee SK, Baik HW, Lee KH, Lee KW, Park KY, Kim BJ: Exendin-4 protects oxidative stress-induced $\beta$-cell apoptosis through reduced JNK and GSK3 $\beta$ activity. J Korean Med Sci 2010, 25:1626-1632.

31. Fujiwara K, Maekawa F, Yada T: Oleic acid interacts with GPR40 to induce $\mathrm{Ca} 2+$ signaling in rat islet beta-cells: mediation by PLC and L-type Ca2+ channel and link to insulin release. Am J Physiol Endocrinol Metab 2005, 289:E670-E677.

32. Salehi A, Flodgren E, Nilsson NE, Jimenez-Feltstrom J, Miyazaki J, Owman C, Olde B: Free fatty acid receptor 1 (FFA(1)R/GPR40) and its involvement in fatty-acid-stimulated insulin secretion. Cell Tissue Res 2005, 322:207-215.

33. Briscoe CP, Peat AJ, McKeown SC, Corbett DF, Goetz AS, Littleton TR, McCoy DC, Kenakin TP, Andrews JL, Ammala C, Fornwald JA, Ignar DM, Jenkinson S: Pharmacological regulation of insulin secretion in MIN6 cells through the fatty acid receptor GPR40: identification of agonist and antagonist small molecules. Br J Pharmacol 2006, 148:619-628.

34. Itoh Y, Kawamata Y, Harada M, Kobayashi M, Fujii R, Fukusumi S, Ogi K, Hosoya M, Tanaka Y, Uejima H, Tanaka H, Maruyama M, Satoh R, Okubo S,
Kizawa H, Komatsu H, Matsumura F, Noguchi Y, Shinohara T, Hinuma S, Fujisawa Y, Fujino M: Free fatty acids regulate insulin secretion from pancreatic beta cells through GPR40. Nature 2003, 422:173.

35. Roger B, Papin J, Vacher P, Raoux M, Mulot A, Dubois M, Kerr-Conte J, Voy BH, Pattou F, Charpentier G, Jonas JC, Moustaïd-Moussa N, Lang J: Adenylyl cyclase 8 is central to glucagon-like peptide 1 signalling and effects of chronically elevated glucose in rat and human pancreatic beta cells. Diabetologia 2011, 54:390-402.

36. Liu J, Farmer JD Jr, Lane WS, Friedman J, Weissman I, Schreiber SL: Calcineurin is a common target of cyclophilin-cyclosporin A and FKBP-FK506 complexes. Cell 1991, 66:807-815.

37. Ishida A, Fujisawa H: Stabilization of calmodulin-dependent protein kinase II through the autoinhibitory domain. J Biol Chem 1995, 270:2163-2170.

38. Ramos LS, Zippin JH, Kamenetsky M, Buck J, Levin LR: Glucose and GLP-1 stimulate cAMP production via distinct adenylyl cyclases in INS-1E insulinoma cells. J Gen Physiol 2008, 132:329-338.

39. Brunet A, Bonni A, Zigmond MJ, Lin MZ, Juo P, Hu LS, Anderson MJ, Arden KC, Blenis J, Greenberg ME: Akt promotes cell survival by phosphorylating and inhibiting a Forkhead transcription factor. Cell 1999, 96:857-868.

40. Eizirik DL, Colli ML, Ortis F: The role of inflammation in insulitis and beta-cell loss in type 1 diabetes. Nat Rev Endocrinol 2009, 5:219-226.

41. Donath MY, Ehses JA, Maedler K, Schumann DM, Ellingsgaard H, Eppler E, Reinecke M: Mechanisms of beta-cell death in type 2 diabetes. Diabetes 2005, 54:S108-S113.

42. Donath MY, Böni-Schnetzler M, Ellingsgaard H, Ehses JA: Islet inflammation impairs the pancreatic beta-cell in type 2 diabetes. Physiology 2009, 24:325-331.

43. de Luca C, Olefsky JM: Inflammation and insulin resistance. FEBS Lett 2008, 582:97-105

44. Vadakekalam J, Rabaglia ME, Chen QH, Metz SA: Role for GTP in glucose-induced phospholipase $\mathrm{C}$ activation in pancreatic islets. Am J Physiol 1996, 271:E85-95.

45. Tian G, Sandler S, Gylfe E, Tengholm A: Glucose- and hormone-induced cAMP oscillations in $\alpha$ - and $\beta$-cells within intact pancreatic islets. Diabetes 2011, 60:1535-1543.

46. Gowda N, Dandu A, Singh J, Biswas S, Raghav V, Lakshmi MN, Shilpa PC, Sunil V, Reddy A, Sadasivuni M, Aparna K, Verma MK, Moolemath Y, Anup MO, Venkataranganna MV, Somesh BP, Jagannath MR: Treatment with CNX-011-67, a novel GPR40 agonist, delays onset and progression of diabetes and improves beta cell preservation and function in male ZDF rats. BMC Pharmacol Toxicol 2013, 14:28

47. Teixeira de Lemos E, Reis F, Baptista S, Pinto R, Sepodes B, Vala H, Rocha-Pereira P, Correia da Silva G, Teixeira N, Silva AS, Carvalho L, Teixeira F, Das UN: Exercise training decreases proinflammatory profile in Zucker diabetic (type 2) fatty rats. Nutrition 2009, 25:330-339.

48. Jourdan T, Godlewski G, Cinar R, Bertola A, Szanda G, Liu J, Tam J, Han T, Mukhopadhyay B, Skarulis MC, Ju C, Aouadi M, Czech MP, Kunos G: Activation of the Nlrp3 inflammasome in infiltrating macrophages by endocannabinoids mediates beta cell loss in type 2 diabetes. Nat Med 2013, 19:1132-40.

doi:10.1186/1471-2121-15-24

Cite this article as: Verma et al: Activation of GPR40 attenuates chronic inflammation induced impact on pancreatic $\beta$-cells health and function. BMC Cell Biology 2014 15:24.

\section{Submit your next manuscript to BioMed Central and take full advantage of:}

- Convenient online submission

- Thorough peer review

- No space constraints or color figure charges

- Immediate publication on acceptance

- Inclusion in PubMed, CAS, Scopus and Google Scholar

- Research which is freely available for redistribution 